\title{
Differential expression of two ATPases revealed by lipid raft isolation from gills of euryhaline teleosts with different salinity preferences
}

\author{
Lin Yu-Ting ${ }^{1,2}$, Hu Yau-Chung ${ }^{1,2}$, Wang Yu-Chun ${ }^{3}$, Hsiao Man-Yun ${ }^{1}$, Lorin-Nebel Catherine 4, ${ }^{*}$, \\ Lee Tsung-Han ${ }^{1,2,{ }^{*}}$
}

1 Department of Life Sciences, National Chung Hsing University, Taichung 402, Taiwan

2 The iEGG and Animal Biotechnology Center, National Chung Hsing University, Taichung 402, Taiwan

3 Planning and Information Division, Fisheries Research Institute, Keelung 202, Taiwan

4 Univ. Montpellier, MARBEC (Univ. Montpellier, CNRS, IRD, IFREMER), 34095 Montpellier, France

* Corresponding authors : Catherine Lorin-Nebel, email address : catherine.lorin@umontpellier.fr ;

Tsung-Han Lee, email address : thlee@email.nchu.edu.tw

\begin{abstract}
:
In euryhaline teleosts, $\mathrm{Na}+, \mathrm{K}+$-ATPase (NKA) and V-type $\mathrm{H}+-$ ATPase A (VHA A) are important iontransporters located in cell membrane. Lipid rafts (LR) are plasma membrane microdomains enriched in cholesterol, sphingolipids, and proteins (e.g., flotillin). Flotillin is a LR-associated protein, commonly used as the LR marker. Previous mammalian studies showed that LR may play a crucial role in ion exchanges. Meanwhile, studies on mammals and rainbow trout showed that NKA were found to be present mainly in LR. However, little is known about LR in fish. Therefore, the present study aimed to investigate the involvement of branchial LR in osmoregulation of tilapia and milkfish, two euryhaline teleosts with different salinity preferences, by (i) extracting LR from the gills of euryhaline teleosts; (ii) detecting the abundance of LR marker protein (flotillin-2) and ion-transporters (NKA and VHA A) in branchial LR and non-LR of fresh water- and seawater-acclimated milkfish and tilapia. The results indicated that the protein abundance of LR marker, flotillin-2, changed with environmental salinities in branchial LR of tilapia. In addition, flotillin-2 and NKA were only found in LR in both tilapia and milkfish gills, while VHA A were mainly present in non-LR. Relative protein abundance of NKA was found to be significantly higher in gills of freshwater milkfish and seawater tilapia, while VHA A was significantly higher in gills of freshwater tilapia and milkfish. This study illustrated differential distribution and salinity-dependent expression of NKA and VHA A in cell membrane of gill tissues of euryhaline teleosts with different salinity preferences.
\end{abstract}




\section{Graphical abstract}

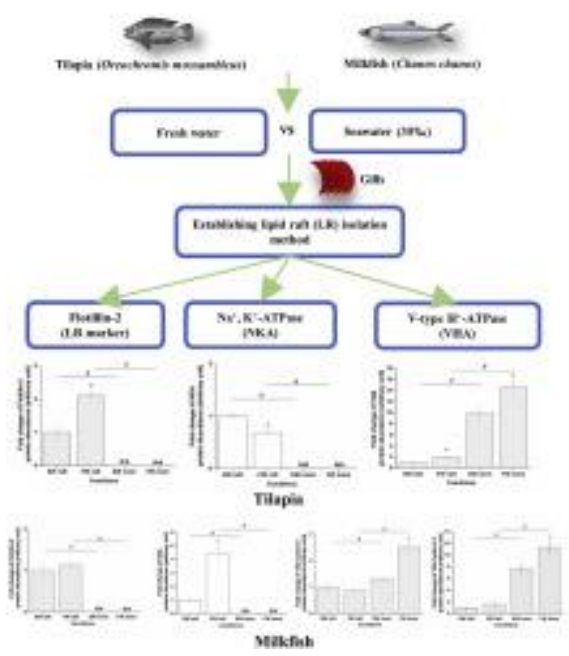

\section{Highlights}

- Lipid raft were extracted from gills of teleosts using nonionic detergents. Flotillin-2 expression is differently affected by salinity among teleost species. $\mathrm{Na}^{+}, \mathrm{K}^{+}$-ATPase is mainly located in lipid raft fractions enriched in flotillin-2. V V-type $\mathrm{H}^{+}$-ATPase is expressed in both, non-lipid raft and lipid raft fractions. Salinity affects $\mathrm{V}$-type $\mathrm{H}^{+}$ATPase expression in non-lipid raft fractions only.

Keywords : osmoregulation, flotillin, $\mathrm{Na}+, \mathrm{K}+-\mathrm{ATPase}, \mathrm{V}$-type $\mathrm{H}+-\mathrm{ATPase}$, euryhaline teleosts 


\section{Introduction}

Lipid raft (LR) are membrane microdomains rich in cholesterol and glycoshpingolipids involved in the organization and aggregation of lipid bilayer constituents including transmembrane proteins (Simons and Ikonen, 1997). LR have been reported to be involved in virus entry (Nguyen and Hildreth, 2000; Ono and Freed, 2001), protein trafficking (Brown and London, 1998), ion transport processes (Tillman and Cascio, 2003) and cell signaling (Varma and Mayor, 1998). Because of their high lipid content, i.e., high lipid-to-protein ratio (Br'sv? anıd Rose, 1992) and relatively low density, the LR fraction can be extractec' fol swing non-ionic detergent treatment using density gradients. LR are highly $d_{;}, a_{1}{ }^{i} c$, usually nanoscale structures that can form bigger raft by means of $f_{\mathcal{A}}$ SIL? of small entities (Lingwood and Simons, 2010). Levental et al. (2010) : hu ved that S-acylation, referred to as 'palmitoylation' plays an important $1.1 \mathrm{e} n$ regulating raft affinity. The binding of palmitate with cysteine residues of ${ }_{\mathrm{r}}{ }^{\mathrm{r}}$ oteins promotes their insertion into the LR fraction and suggests that palmito, 10 ion plays a critical role in membrane targeting mechanisms involving trar merıbrane proteins (Resh, 2006). According to Levental et al. (2010) and Contrel ¿s e al. (2011), among plasma membrane proteins, about $65 \%$ were in the nu -1 m. phase, whereas $12 \%$ required palmitoylation for raft phase inclusion, $11 \%$ were glycosylphosphatidylinositol (GPI)-anchored in the raft, and the other $11 \%$ could be bound to LR lipids such as cholesterol or sphingolipids (SLs).

Lipid compositions of the LR and non-LR fractions are considered to be different as shown in common carp (Cyprinus carpio), i.e., the LR fraction contained a higher percentage of cholesterol and non-polar lipids (Brogden et al., 2014). Non-ionic detergents are thus used to extract LR (also called detergent-resistant membranes (DRM)) from other cell membranes (Eckert et al., 2003; Dalskov et al., 2005; Lingwood et al., 2005). Commonly used detergents for LR extraction in mammalian 
studies include CHAPS, Tween 20, Triton X-100, Lubrol WX, Brij96, and Brij98, and different detergents that may cause different result of lipid raft isolation due to the dissolvability (Drevot et al., 2002; Madore et al., 1999; Röper et al., 2000; Schuck et al., 2003). Among them, Triton X-100 is the most commonly used detergent for LR extraction (Foster and Chan, 2007; Pike, 2006; Schroeder et al., 1998). Triton X-100 has also been applied in LR research with various protocols in skate (Raja erinacea; Musch at al., 2004), rainbow trout (Lingwood et al., 2005), Atlantic cod (Gadus morhua; Gylfason et al., 2010), goldfish (Carassius aurat' „, Táicia-Garcia et al., 2012), and common carp (Brogden et al., 2014). Previ , us . tudies on fish have not compared different detergents and have not quantif: ${ }^{\text {q }}$. Totillin-2 following LR isolation. Brogden et al. (2014) found that lipid $c \mathrm{~s}_{\mathrm{r}}$ רsition of plasma membrane in common carp was different from that in ht $m_{a^{n}}$ and the lipid components were organ-dependent, whether in LR or $1, n-L R$ regions. In their results, even $0.1 \%$ of Triton X-100 cannot perfectly isola` flotillin-2 in LR from non-LR region in all tissue. As a result, it is important $\mathrm{t}$ 'est different concentration of detergents.

Flotillins are LR-asso iatec proteins commonly used as markers for LR. Plasma membrane targeting and ' $\mathrm{l}$ ' tering of flotillins on LR mainly relies on acylation (myristoylation or $\mathrm{f} / \mathrm{l}$.... been shown to be involved in some basic functions such as trafficking and transport of membrane materials and proteins (Stuermer, 2010). Flotillins are divided into two isoforms. Flotillin-1 (previously named reggie-2) seems to associate with raft by means of the first hydrophobic domain (Liu et al., 2005) and has also been shown to be palmitoylated in Cys34, which is essential for flotillin-1 to locate on the cytoplasmic side of the plasma membrane (Morrow et al., 2002). Flotillin-2 (previously named reggie-1) interacts with the plasma membrane through several sites of palmitoylations and myristoylations, and plays a significant role in the maintenance 
of membrane raft (Neumann-Giesen et al., 2004, Langhorst et al., 2006). Evidence of flotillin function in fish is scarce. In zebrafish (Danio rerio), von Philipsborn et al. (2005) suggested that flotillin might be involved in development.

The LR plays important roles in ionoregulation and osmoregulation, as shown by proteins responsible for ion transport being localized to LR, including active transport pumps/enzymes (i.e., ATPase) (Tillman and Cascio, 2003; Murtazina et al., 2006). For example, the $\mathrm{Na}^{+}, \mathrm{K}^{+}$-ATPase (NKA) in fish branchial and renal cells (Lingwood et al., 2005; Welker et al. 2007) and vacuolar-type $\mathrm{H}^{+}$-ATPas_- ('tiA) in mammalian cells (Lafourcade et al., 2008).

Membrane structure and transmembrane enzrme ? $n$ nction are linked because the lipid environment of the enzyme can constrain pr ste ${ }_{1}$. motions required for catalysis, affecting the enzyme catalytic rate (Harris, $1>^{25}$, Cossins et al., 1986). Among the enzymes/transporters, the NKA catai, '7e, the transport of $\mathrm{Na}^{+}$and $\mathrm{Cl}^{-}$across epithelia in both absorptive (fresh water; FW , and secretory (seawater; SW) modes in gills of euryhaline teleosts (Marshall, 200'• Perry et al., 2003; Hirose et al., 2003). Changes in branchial NKA activity $:$ eur yhaline fish are necessary for acclimation to environmental salinity (เ`ar hall and Bryson, 1998; Kelly et al., 1999; Marshall, 2002; Mancera et al., 20七? .... ose et al., 2003; Lin et al., 2003; Scott et al., 2004). Furthermore, NKA consists of $\alpha$ - and $\beta$-subunits (Scheiner-Bobis, 2002). The $\alpha$-subunit has a molecular weight of about $100 \mathrm{kDa}$ and is considered the catalytic center of the NKA, with binding sites for cations, ATP, and ouabain (NKA inhibitor). The $\beta$-subunit, with a molecular weight of $40-60 \mathrm{kDa}$, can stabilize the structure and regulate the cations affinity of the $\alpha$-subunit on the plasma membrane (Skou and Esmann, 1992; Abriel et al., 1999). Moreover, reciprocal interactions between NKA and cholesterol or phospholipids have been proposed (Chen et al., 2011; Cornelius, 2008; Cornelius et al., 2015; Haviv et al., 2013; Kravtsova et al., 2015) and NKA 
distribution on LR has been reported in previous studies on mammalian tissues (Welker et al., 2007). Using the Brij 98 (as a non-ionic detergent) to extract the granulocytes in the brain of rat also revealed the presence of NKA $\alpha$-subunits in LR (Dalskov et al., 2005). However, there are few studies focused on fish NKA in LR. In gills of rainbow trout (Oncorhynchus mykiss), NKA are expressed in LR when transferred to SW but not detected in LRs in FW individuals, indicating different strategies in ionoregulation between $\mathrm{FW}$ - and SW-acclimated rainbow trout (Lingwood et al., 2005). Most reports on NKA $\alpha$-subunit, '.1v vever, focused on their localization on the basolateral plasma membrane and t' ieir 'xpression when fish encountered different environmental salinities (Ler st a'., 2003; Lin et al., 2003). The NKA $\alpha$-subunit protein abundance in gills of FW pre: ${ }^{*}$ rence Mozambique tilapia (Oreochromis mossambicus) was significa tt, h: gher in SW than in FW (Lee et al. 2003), while in gills of SW-preferen ${ }^{\sim} \mathrm{r}$.llkfish (chanos chanos) it was significantly higher in FW than in SW (Lin et al., 2003).

The VHA is a multi-subunit ( $a p l e x$ organized into two domains: the $650 \mathrm{kDa}$ cytosolic $\mathrm{V}_{1}$ domain and th $\cdot 26 \mathrm{kDa}$ membrane-embedded $\mathrm{V}_{0}$ domain (Nishi and Forgac, 2002; Forgac, 2(77· Toei et al., 2010). In previous mammalian studies, deprivation of choı stc,$u$ from LR resulted in the decrease of electrogenic $\mathrm{H}^{+}$efflux by VHA and in synaptic signaling deficiency (Yoshinaka et al., 2004). On frog and insect epithelial cells, VHA contributed to acid-base regulation and osmoregulation (Harvey et al., 1998). In the studies on rainbow trout gills, VHA activity and immunoreactivity decreased when FW trout were acclimated to SW (Lin and Randall, 1993; Lin et al., 1994). In the Atlantic stingray (Dasyatis sabina) and killifish (Fundulus heteroclitus), VHA expressed on the cell membrane was significantly higher in FW than in SW (Piermarini and Evans, 2001; Katoh et al., 2003). As a result, this consistently higher expression of VHA in FW environments is linked to its role in 
generating an electrical gradient favoring $\mathrm{Na}^{+}$uptake in $\mathrm{FW}$-type ionocytes, additional to its role in acid secretion. In tilapia, bafilomycin, an inhibitor of VHA, has been shown to affect in vivo $\mathrm{Na}^{+}$influx (Fenwick et al., 1999), indicating a key role of this pump in freshwater osmoregulation in tilapia and suggesting an apical location in ionocytes.

To date, most studies on NKA and VHA in fish focus on their relationship with cell membrane, while the relationship between NKA and LR in fish was only reported in the rainbow trout (Lingwood et al., 2005). On the other 'an'ds, there is no reference reporting the associations of VHA and LR in fish. Acc rrd. 'g to previous references, this study hypothesized that NKA and VHA, the main $^{\text {in }}$ on pumps in fish gills, may be mainly distributed in the LR to be involved in ior. orte ${ }^{-1}$ lation of euryhaline teleosts

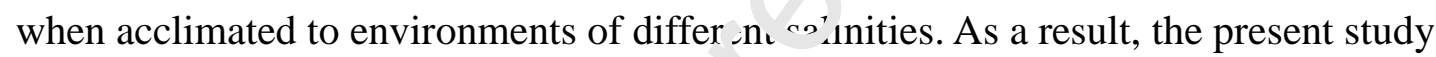
aims to investigate the presence of L' a d their exhibition of NKA and VHA in gills of tilapia (the FW euryhaline teleosı, and milkfish (the marine euryhaline teleost), by (i) extracting membrane LR frnm ¿i's of tilapia and milkfish, with fresh water (FW) and seawater (SW) prefere: ses, iespectively, and (ii) assessing differential NKA and VHA expression in branı hia. LR between FW- and SW-acclimated milkfish and tilapia. This study ${ }^{\circ}{ }^{\circ}$ vi.ies the evidence for expression of critical ion transporters in LR of euryhaline teleosts with different salinity preferences. Differential expression of flotillin-2 (the LR marker) and two ATPases, the ATP-consuming NKA and VHA, in gills of euryhaline fish will further clarify the ionoregulation roles of branchial LR in environments of different salinities. 


\section{Materials and methods}

\section{Experimental fish and design}

Mozambique tilapia (Oreochromis mossambicus), and juvenile milkfish (Chanos chanos) were obtained from laboratory stocks and a local fish farm, respectively, with average standard lengths of $5.5 \pm 0.5$, and $10.6 \pm 0.4 \mathrm{~cm}$, respectively. Seawater (SW; $35 \%$ ) and brackish water (BW; $15 \%$ ) used in this study were prepared from aerated tap water (FW) with artificial sea salt (Synthetic Sea Salt; Blue Treasure, Qingdao, China). The water was continuously circulated through far in -tıss filters and quarter of water was changed every two weeks. The ammonia con. ents were routinely examined using the commercial API ${ }^{\circledR}$ ammonia te ${ }^{*} k_{k}$ t. Quarter of water was changed when the ammonia level was higher than $0 \mathrm{ppm}$. Zac: species of fish was reared in four separated tanks at $28 \pm 1^{\circ} \mathrm{C}$ in $\mathrm{BW}$ for th $\cdots$ reeks before transfer to either $\mathrm{FW}$ or $\mathrm{SW}$, with a daily $12 \mathrm{~h}$ photoperiod ai ${ }^{\mathrm{f}}$ a daily diet of commercial pellets. The holding densities of tilapia and milkfish in $\mathrm{c}$. $\mathrm{ch}$ tank were $0.4 \mathrm{fish} / \mathrm{L}$ and $0.2 \mathrm{fish} / \mathrm{L}$, respectively.

For establishing the p: tocul of lipid raft (LR) extraction, tilapia and milkfish were reared in FW and $\mathrm{S}^{\mathrm{V}}$. espectively, for at least four weeks before sampling the gills. Differential e nuvolon of NKA and VHA in branchial LR was further assessed between FW and SW in each species after one-month acclimation. For subsequent analyses, six individuals of either FW or SW groups were used for experiments and four gill arches from the right opercular side of each fish were sampled. Before sampling, experimental fish were not fed for one day and anesthetized in $500 \mu \mathrm{L} / \mathrm{L}$ 2-phenoxyethanol. The protocol used for the experimental fish was reviewed and approved by the Institutional Animal Care and Use Committee of the National Chung Hsing University (IACUC approval no. 102-09R and 105-130 to T.H. Lee). 


\section{Preparation of crude membrane fractions, lipid raft and non-lipid raft fractions}

Gill tissues from the experimental fish were steeped in a mixture of homogenization buffer (SEI buffer, $150 \mathrm{mM}$ sucrose, $10 \mathrm{mM}$ EDTA, $50 \mathrm{mM}$ imidazole, $\mathrm{pH}$ 7.4) with commercial protease inhibitor cocktail (Roche, Mannheim, Germany; 1:50, v/v). Homogenization was performed with a Polytron PT1200E (Kinematica, Lucerne, Switzerland). After the first centrifugation $\left(1,500 \mathrm{~g}\right.$ at $4^{\circ} \mathrm{C}$ for $10 \mathrm{~min}$ ), the pellets were discarded and the supernatants were centrifuged again $\left(13,000 \mathrm{~g}\right.$ at $4^{\circ} \mathrm{C}$ for $\left.12 \mathrm{~min}\right)$. After the second centrifugati $\boldsymbol{J n}_{\mathbf{1}}$, thu supernatants were retained and centrifuged a third time $\left(20,800 \mathrm{~g}\right.$ at $4^{\circ} \mathrm{C} f$ or $\left.\left.\mathrm{c}\right) \mathrm{min}\right)$. Then after the third centrifugation, the supernatants as the cytosol was disc.rded. Meanwhile, the pelleted fraction containing large fragments of the plasm? mt. nbrane was retained and considered as the crude membrane fractior ( crude membrane fraction was furthe, dir solved to obtain the lipid raft using SEI buffer with $0.1 \%$ or $0.05 \%$ Triton $\mathrm{X} \cdot 100$ or $0.05 \%$ Tween 20 (abbreviated as SEIT) at $4^{\circ} \mathrm{C}$ (Brogden et al., 2014). Aftor c is ,olution in detergents at different time points (30, 60 and/or $120 \mathrm{~min}$ ) to dete: nint the best duration of digestion, the aliquots were centrifuged $\left(20,800 \mathrm{~g}\right.$ at ${ }^{10} \mathrm{C}$ for $\left.30 \mathrm{~min}\right)$. The supernatants of the fourth centrifugation was considered as …utergent-soluble membrane (non-LR). The pellet as the detergent-insoluble membrane (LR) was then dissolved by the protease inhibitor cocktail (Roche) contained SEID buffer (150 mM sucrose, $10 \mathrm{mM}$ EDTA, $50 \mathrm{mM}$ imidazole, $0.5 \%$ sodium deoxycholate, $\mathrm{pH} 7.4$ ) because LR can be dissolved in deoxycholate (McGuinn and Mahoney, 2014). Protein concentrations were measured with reagents from the Pierce ${ }^{\mathrm{TM}} \mathrm{BCA}$ protein assay kit (Thermo Fisher, Rockford, IL, USA) using bovine serum albumin (Thermo Fisher) as standard.

\section{Antibodies}


The primary antibodies used in this study included (i) a mouse monoclonal antibody ( $\alpha 5$, DHSB, Iowa City, IA, USA) raised against the avian NKA $\alpha$-subunit (Lin et al., 2003; Yang et al., 2015), (ii) a mouse monoclonal antibody (flotillin-2, Santa Cruz, CA, USA) raised against the amino acids 150-240 of human flotillin-2 (XP_016879883.1) with approximately 83\% similarity with milkfish flotillin-2 (XP_030648347.1) and 80\% similarity with tilapia flotillin-2 (XP_003456181.1), and (iii) a rabbit polyclonal antibody (MDBio, Taipei, Taiwan) raised against the specific epitope (AEMPADSGYPAYLGARLA) of the pufferfish ("*avadon nigroviridis) VHA A (ABX80240.1) with $100 \%$ similarity with mil fisi VHA A isoform1 and isoform 2, as well as tilapia VHA A (BAF94024.1) Th sequences of two isoforms of VHA A found in the milkfish transcriptome datar ase 'Hu et al., 2015) were showed in Fig. S1. The specificities of the VHA A an ib dy to gills of tilapia and milkfish were tested and showed in Fig. S2. Accorı $\eta$ co the primary antibodies, the secondary antibodies for immunoblots includt. ${ }^{\top}$ the horseradish peroxidase-conjugated (i) rabbit anti-mouse IgG, (ii) goat anti-rabt it $\mathrm{gG}$, and (iii) rabbit anti-goat IgG (GeneTex, Irvine, CA, USA). The sim.' arity between flotillin-2 with milkfish.

\section{Immunoblotting}

The sample mixture of $6 \mathrm{x}$ sample loading dye ( $0.06 \%$ bromophenol blue, $30 \%$ glycerol, 12\% SDS, 0.6 M dithiothreitol, and 62.5 mM Tris with $\mathrm{pH} 6.8$ ) and gill proteins $(1: 5, \mathrm{v} / \mathrm{v})$ was heated at $65^{\circ} \mathrm{C}$ for $15 \mathrm{~min}$ to denature the proteins. Non-LR and LR samples were separated by electrophoresis on a 7\% SDS-polyacrylamide gel ( $5 \mu \mathrm{g}$ of protein per lane) using a Mini-protein II electrophoresis cell (Bio-Rad, Hercules, CA, USA). Then, the separated proteins were transferred to polyvinylidene difluoride (PVDF) membranes (Millipore, Bedford, MA, USA). After incubation in the non-specific blocking solution using phosphate buffer saline with Tween 20 
(PBST; $2.68 \mathrm{mM}$ potassium chloride, $10.1 \mathrm{mM}$ disodium phosphate, $137 \mathrm{mM}$ sodium chloride, $1.76 \mathrm{mM}$ potassium dihydrogen phosphate, and $0.2 \%$ (v/v) Tween; $\mathrm{pH} 7.4$ ) containing $5 \%(\mathrm{w} / \mathrm{v})$ nonfat dried milk for $2 \mathrm{~h}$ at room temperature (RT), the blots were incubated overnight with the primary antibody $(1: 5000)$ at $4^{\circ} \mathrm{C}$, followed by washing the membranes with PBST. Then the membranes were incubated with the secondary antibody $(1: 25000)$ for $1 \mathrm{~h}$ at RT. Images were developed with T-Pro LumiLong Chemiluminescent Substrate Kit (Ji-Feng Biotechnology, New Taipei, Taiwan) under a cooling-CCD (charge-couple device) cam w. (ChemiDoc XRS+, Bio-Rad) with associated software (Quantity One vers on : 6.8, Bio-Rad). The blot bands were converted to numerical values by $\operatorname{Imar}_{2}=$ ai 3.0 software (Bio-Rad) to quantify and compare relative protein abundance of $\therefore$ immunoreactive bands.

\section{Statistics}

In this study, comparisons in flotilı -2 , NKA- $\alpha$ or VHA A abundance between (i) LR and non-LR fractions of gills in ei hr, r SW or FW fish, or (ii) SW or FW groups in either LR or non-LR fractic ns, I sspectively, were analyzed by the Student's $t$-test, with $\mathrm{p}<0.05$ was set as . he ignificant level. Values are expressed as means \pm S.E.M.

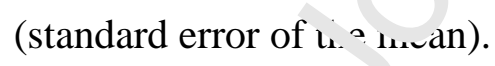




\section{Results}

\section{Separation and purification of LR from tilapia and milkfish gills}

In tilapia (Fig. 1), the crude membrane fraction was first reacted in the non-ionic detergent Triton X-100. After 30, 60, and 120 minutes of reaction with this detergent at $0.1 \%$ as well as 60 minutes of reaction at $0.05 \%$, strong immunoreactive bands were found in LR for NKA $\alpha$-subunit and flotillin-2. However, faint immunoreactive bands of both proteins were found in non-LR, indicating that dissolvability of 0.1 and 0.05\% Triton X-100 may not be optimal for tilapia gill tis a (I ig. 1). Meanwhile, the supernatant separated by reacting with $0.05 \%$ Twer $n-\angle$ ? for 60 minutes did not show immunoreactive bands of flotillin-2 in non-J $\mathbf{n}$ 1. dicating the better dissolution of this protocol for extracting LR from tilapia gil's ( $(\because \mathrm{g}$. 1). Moreover, no band for NKA $\alpha$-subunit was observed in the non-L? $\mathrm{i}$ ar ion.

In milkfish (Fig. 2), similar resu'ts nere observed at 30-minutes treatments with the non-ionic detergent $0.1 \%$ Triton X-100 as tilapia reacted with Triton X-100 (Fig. 1). However, after 60 and 120 mir ' it is of reaction with $0.1 \%$ Triton $X-100$, there was no flotillin-2 and NKA $\alpha$-s. hunı immunoreactive band found in the non-LR membrane fraction, indı tir $g$ that the LR of milkfish gills could be separated after $0.1 \%$ Triton $\mathrm{X}-10 \mathrm{w}$ disurution following 60 minutes of incubation. The NKA $\alpha$-subunit abundance was high in the LR fraction (Fig. 2). Hence, extraction of LR by $0.1 \%$ Triton $\mathrm{X}-100$ for 60 minutes is an appropriate procedure for LR purification from milkfish gills.

\section{Comparisons of flotillin-2 and NKA in branchial LR and non-LR fractions between FW and SW tilapia and milkfish}

As illustrated in Fig. 1, tilapia gills treated with $0.05 \%$ Tween-20 for 60 minutes revealed better dissolvability in LR membrane fractions. This condition has thus been 
used to compare salinity effects on LR and non-LR gill fractions of tilapia. Flotillin-2 and NKA $\alpha$-subunit protein levels were only detected in the LR of both FW and SW tilapia. The abundance of flotillin-2 in LR was significantly (2 times) higher in the FW group than in the SW group (Fig. 3A). On the contrary, the abundance of NKA $\alpha$-subunit in LR of SW tilapia was 1.4 times higher than that of FW fish (Fig. 3B).

Similarly, flotillin-2 and NKA $\alpha$-subunit protein levels were only detected in the LR of both FW and SW milkfish using $0.1 \%$ Triton X-100 as detergent for 60 minutes (Fig. 4). In milkfish LR, no significant difference was four $u$ : $\eta$ tile abundance of flotillin-2 between FW and SW groups (Fig. 4A). Sign ficintly higher (4.4 times) NKA $\alpha$-subunit abundance was detected in LR of $F \mathbf{r} /$-ilkfish compared to the SW LR group (Fig. 4B).

\section{Comparisons of VHA A abundance in oranchial LR and non-LR fractions between FW and SW tilapia and .. ilkfish}

In tilapia, a specific immino an ctive band of $69 \mathrm{kDa}$ was detected in branchial LR and non-LR fractions ( ig. $\mathrm{AA})$. Most VHA A was located in the non-LR (mem) compared to LR. In addı: $n$, significant higher VHA A abundance was detected in both non-LR (men, an a $^{2}$ LR fraction of the FW group compared to those of the SW group. (Fig. 5B).

Two immunoreactive bands corresponding to 69 and $60 \mathrm{kDa}$ were detected as the isoform 1 and 2, respectively, of the VHA A subunit of milkfish gills (Fig. 6A). Similar to tilapia VHA A, relative abundance of milkfish VHA A isoform 1 and 2 was significantly higher in the non-LR fraction rather than the LR fraction (Fig. 6B, 6C). Moreover, significantly higher amounts of both isoform 1 (about 2 times; Fig. 6B) and isoform 2 (about 1.5 times; Fig. 6C) of milkfish VHA A subunit were found in the non-LR fraction of the FW group compared to the SW group. In the LR fraction 
of gills, however, no significant difference was found between FW and SW milkfish in either isoform 1 (Fig. 6B) or isoform 2 (Fig. 6C) of VHA A subunit. 


\section{Discussion}

This study revealed that Triton X-100 had better dissolvability for extracting LR from gills of milkfish rather than tilapia due to the weakly immunoreactive bands of flotillin and NKA found in the non-LR fractions of tilapia gills. LR and non-LR membrane regions of tilapia were isolated more efficiently using Tween 20 as detergent. LR extraction efficacy from Madin-Darby canine kidney (MDCK) cells has been previously reported for various surfactants. It was found that the membrane dissolving effects of Triton X-100 and CHAPS used to $\mathrm{ex}^{\dagger}$ an $^{+}{ }^{t} \mathrm{t}$ e LR-protein were 10 times higher than using Tween 20, Brij58, and Lubrol N NX. Moreover, the Madin-Darby canine kidney (MDCK) cell and MFrk ells expressing human PLAP (MDCK-PLAP) cell revealed better results in LR exı ' 7 ction by using Triton X-100 as a detergent compared to Tween 20 , indicat $n_{5}{ }^{\text {th }}$ t Triton X-100 had a higher ability to dissolve lipid structures than Tween $\cdot n$ (jchuck et al., 2003).The detergent efficacy results in this study also showed tha' the strength of the detergents required for LR extraction in various fish specias c if'ered and thus had to be adjusted for each species in order to have optimal $\mathrm{L} \Gamma$ isolutions. It has to be noted that when different detergents are used, LR ८ >m position might be slightly different (Schuck et al., 2003). Differences in SLs - nci inolesterol-rich fatty acids abundance found among various species may lead to different efficacy of detergents (Schuck et al., 2003; Lingwood et al., 2005; Brogden et al., 2014). As a result, different efficacy of detergents between tilapia and milkfish found in this study might be attributed to more abundant SLs and cholesterol-rich fatty acids in LR of milkfish than tilapia, requiring a more efficient detergent to extract LR from other portions of the membranes.

LR are known to act as signaling and sorting platforms for numerous molecules (Simons and Toomre, 2000; Smart et al., 1999), and proteins forming the scaffolding of LR (Babuke et al., 2009). Flotillins have generally been used as marker proteins for 
LR (Bickel et al., 1997; Neumann-Giesen et al., 2004, 2007). In addition, specific GPI-anchored proteins have been observed to co-cluster with flotillins. So, flotillins have been proposed to represent centers for GPI-anchored proteins' communication with intracellular signal transduction molecules (Stuermer and Plattner, 2004). They have also been reported to play the roles in trafficking and transport of membrane proteins and materials (Stuermer, 2010). Our results in different species provided evidence that LR are differentially expressed in different euryhaline fish regarding salinity acclimation by assessing the expression patterns $0^{5}=$ LR marker, flotillin- 2 . LR abundance (i.e., flotillin-2 abundance) in gills was ;igh ficantly higher in FW than in SW tilapia while there was slightly but not signif: $a_{1}$ tly higher expression of flotillin-2 in gills of FW compared to SW milkfisi. Lifferential LR abundance might affect transporter function, as the membrar $e_{\perp_{1}}$ ni $_{\perp}$ environment is essential for the functioning of transporters and chanı. $1 s$. Until now, evidence on the link between LR and salinity acclimation was only $\mathrm{rc}_{1}$,orted in few species. In skate, the anion exchanger 1, for example, was nre $e_{\text {.t }}$ in intracellular vesicles in detergent-insoluble lipid raft in isotonic condit: ns and shifted to detergent-soluble plasma membrane regions through exocytos: $s$ f Jllowing hypotonicity treatment (Musch et al., 2004).

NKA $\alpha$-subun ${ }^{+}$Drvein abundance (membrane fractions protein) in gills of FW-preference tilapia was significantly higher in SW than in FW (Lee et al. 2003; Lin et al., 2004), while in gills of SW-preference milkfish it was significantly higher in FW than in SW (Lin et al., 2003). This study further revealed that average LR abundance in tilapia gills was significantly higher (two folds) in the FW group than the SW group, while in milkfish gills LR abundance was similar between FW and SW individuals. In addition, the presence of NKA proteins in LR is positively correlated to NKA activities because they were also reported to be higher in gills of the FW milkfish (Lin et al., 2003) as well as SW tilapia (Uchida et al., 2000). Our results thus 
echoed previous studies on NKA expression in membrane fractions of fish gills in tilapia and milkfish (Lee et al. 2003; Lin et al., 2003; Lin et al., 2004).

The immunoblots of this study clearly showed high and low abundance of VHA in the non-LR and LR fraction, respectively, of milkfish and tilapia. Contrary to NKA, VHA is more abundant in non-lipid raft fractions and salinity modulation affects only the expression of VHA in those membrane fractions. In FW non-LR fractions, VHA expression was increased compared to SW non-LR fractions in both species. Moreover, this study is the first to reveal the distribution ${ }^{2}=H_{r s}$ in both LR and non-LR regions of cell membrane in gills of euryhalin ter osts. The presence of VHA mostly found in non-LR fractions may be due to diffel ntial membrane compositions between apical and basolateral membranes with $r \mathrm{~m}_{a}{ }^{i} \eta_{\mathrm{n}}$ to be clarified in future studies.

\section{Conclusion}

The present study set up the 1 if ihod of LR isolation by extracting the LR from two species of euryhaline t leosıs with different salinity preferences. The results indicated that lipid raft $1 \mathrm{~s}$-la ion should be optimized in different species using different detergents ? 1 c.uergent concentration. Accordingly, NKA was found to distributed exclusively in the LR fraction of both tilapia and milkfish gills. The FW euryhaline species (tilapia) has more abundant (two folds) LR in its native media and about $25 \%$ lower NKA expression. The marine euryhaline species (milkfish), however, does not alter LR abundance following salinity changes but increases massive amounts of NKA in the LR fraction. Meanwhile, VHA was first found to be mostly distributed in non-LR fraction where salinity-mediated alterations also occurred in both euryhaline species. Relative VHA abundance in the non-LR fraction was significantly higher in the FW group than the SW group of both euryhaline teleosts 
regardless of their salinity preferences. With successful separation of LR and non-LR fractions from the crude membrane of fish gills, this study deepened our understanding in distribution of two important ion transporters, NKA and VHA, in cell membranes of euryhaline fish gills under different salinities.

\section{Acknowledgements}

This work was financially supported in part by the Integrc tive Evolutionary Galliform Genomics (iEGG) and Animal Biotechnology Center $f$ om The Feature Area Research Center Program within the framework of $t_{1} \cdot$ Higher Education Sprout Project by the Ministry of Education (MOE), Tai van MOE-109-S-0023-A) to T.H.L. This study was also financially supported in part jy $ڤ$ MOST (Ministry of Science and Technology, Taiwan) Research Project (MJTT-109-2313-B-005-005-MY3) to T.H.L. and the Taiwan-France ORCHIn $\mathrm{g}_{2}$ ?nts (MOST-108-2911-I-005-507) to T.H.L. and C.L.N..

\section{Competing interests}

No competing interests $d_{\imath} \cdot a_{\imath} \curvearrowright d$. 


\section{References}

Abriel H., Hasler U., Geering K., Horisberger J.D. 1999. Role of the intracellular domain of the $\beta$ subunit in $\mathrm{Na}, \mathrm{K}$ pump function. Biochim Biophys ActaBiomembranes 1418:85-96.

Banning A., Tomasovic A., Tikkanen R. 2011. Functional aspects of membrane association of reggie/flotillin proteins. Curr Protein Pept Sci 12:725-735.

Babuke, T., Ruonala, M., Meister, M., Amaddii, M., Genzler, C., Esposito, A., Tikkanen, R. 2009. Hetero-oligomerization of reggie-1/flotillin-2 and reggie-2/flotillin-1 is required for their endocytosis. Cellular signalling, 21(8), 1287-1297.

Bickel P.E., Scherer P.E., Schnitzer J.E., Oh P., Lisanti M.r , Lodish H.F. 1997. Flotillin and epidermal surface antigen define a ne $\mathrm{N}$ ta mily of caveolae-associated integral membrane protein . S Siol Chem 272:13793-13802.

Brogden G., Propsting M., Adamek M., Naim H. .., steinhagen D. 2014. Isolation and analysis of membrane lipids and lipid $\mathrm{r}_{\mathrm{a}}$. . in common carp (Cyprinus carpio L.). Comp Biochem Physiol F K « rchem Mol Biol 169:9-15.

Brown D.A., London E. 1998. Functions of lipiu raft in biological membranes. Annu Rev Cell Dev Biol 14:111-12,

Brown D.A., Rose J.K. 1992. Sorting or FPI-anchored proteins to glycolipid-enriched

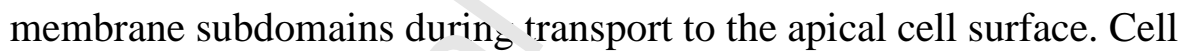
68:533-544.

Chen Y., Li X., Ye Q., Tian ? Jiıg R., Xie Z. 2011. Regulation of $\alpha 1$ Na/K-ATPase expression by choles +erol. J Biol Chem 286:15517-15524

Contreras F.X., Ernst A. M., Vieland F., Brugger B. 2011. Specificity of intramembrar e $p_{1}$ tein-lipid interactions. Cold Spring Harb Perspect Biol 3:a004705.

Cornelius F. 2008. Cisolesterol-dependent interaction of polyunsaturated phospholipids with Na,K-ATPase. Biochemistry 47:1652-1658.

Cornelius F, Habeck M, Kanai R, Toyoshima C, Karlish SJ. 2015. General and specific lipid-protein interactions in Na,K-ATPase. Biochim Biophys Acta 1848:1729-1743.

Cossins A.R., Lee J.A.C., Lewis R.N., Bowler K. 1986. The adaptation to cold of membrane order and $\left(\mathrm{Na}^{+} / \mathrm{K}^{+}\right)$-ATPase properties. In: Heller $\mathrm{HC}(\mathrm{Ed}) \mathrm{Living}$ in the Cold. Elsevier Amsterdam pp:77-90.

Dalskov S.M., Immerdal L., Niels-Christiansen L.L., Hansen G.H., Schousboe A., Danielsen E.M. 2005. Lipid raft localization of GABAA receptor and $\mathrm{Na}^{+}$, $\mathrm{K}^{+}$-ATPase in discrete microdomain clusters in rat cerebellar granule cells. 
Neurochem Int 46:489-499.

Drevot P., Langlet C., Guo X.J., Bernard A.M., Colard O., Chauvin J.P., He H.T.

2002. TCR signal initiation machinery is pre-assembled and activated in a subset of membrane raft. The EMBO journal 21:1899-1908.

Eckert G.P., Igbavboa U., Müller W.E., Wood W.G. 2003. Lipid raft of purified mouse brain synaptosomes prepared with or without detergent reveal different lipid and protein domains. Brain research 962:144-150.

Fenwick J. C., Bonga S. W., Flik G. 1999. In vivo bafilomycin-sensitive Na (+) uptake in young freshwater fish. Journal of Experimental Biology, 202(24), 3659-3666.

Forgac M. 2007. Vacuolar ATPases: rotary proton pumps in 1 hysiology and pathophysiology. Nat Rev Mol Cell Biol 8:917 ภટ?

Foster L.J., Chan Q.W. 2007. Lipid raft proteomics: noı = nan just detergent-resistant membranes. Subcell Biochem 43:35-47.

Garcia-Garcia E., Grayfer L., Stafford J.L., Belosev. M. 2012. Evidence for the presence of functional lipid raft in in $m$ 're cells of ectothermic organisms. Dev Comp Immunol 37:257-269.

Gylfason G. A., Knútsdóttir E., Ásge rss' n B. 2010. Isolation and biochemical characterisation of lipid raft fron. Atlantic cod (Gadus morhua) intestinal enterocytes. Comp Biochem Thysiol B Biochem Mol Biol 155:86-95.

Harris W.E. 1985. Modulation oi (N: , K $\left.{ }^{+}\right)$-ATPase activity by the lipid bilayer examined with dansy' 'tea phosphatidylserine. Biochemistry 24:2873-2883.

Harvey W.R., Maddrell S h. Telfer W.H., Wieczorek H. 1998. H ${ }^{+}$V-ATPases energize animal ^lası ua membranes for secretion and absorption of ions and fluids. Am Zr ol s ९:426-441.

Haviv H., Habeck R. Kanai R., Toyoshima C., Karlish S.J. 2013. Neutral phospholipicus stimulate $\mathrm{Na}, \mathrm{K}-\mathrm{ATPase}$ activity: a specific lipid-protein interaction. J Biol Chem 288:10073-10081.

Hirose S., Kaneko T., Naito N., Takei Y. 2003. Molecular biology of major components of chloride cells. Comp Biochem Physiol B Biochem Mol Biol, 136:593-620.

Hu Y.C., Kang C.K., Tang C.H., Lee T.H. 2015. Transcriptomic analysis of metabolic pathways in milkfish that respond to salinity and temperature changes. PLoS One 10:e0134959.

Katoh F., Hyodo S., Kaneko T. 2003. Vacuolar-type proton pump in the basolateral plasma membrane energizes ion uptake in branchial mitochondria-rich cells of killifish Fundulus heteroclitus, adapted to a low ion environment. J Exp Biol 
206:793-803.

Kelly S.P., Chow I.N., Woo N.Y. 1999. Haloplasticity of black seabream (Mylio macrocephalus): hypersaline to freshwater acclimation. J Exp Zool 283:226-241.

Kravtsova V.V., Petrov A.M., Vasil'ev A.N., Zefirov A.L., Krivoi I.I. 2015. Role of cholesterol in the maintenance of endplate electrogenesis in rat diaphragm. Bull Exp Biol Med 158: 298-300.

Lafourcade C., Sobo K., Kieffer-Jaquinod S., Garin J., Van Der Goot F.G. 2008. Regulation of the V-ATPase along the endocytic pathway occurs through reversible subunit association and membrane localization. PloS one 3:e2758.

Langhorst M.F., Reuter A., Stuermer C.A. 2006. Scaffoldin. microdomains and beyond: the function of reggie/flotillin proteins. C :Il ^ ${ }^{\top} \mathrm{O}$ Life Sci 62:22282240.

Lee T. H., Feng S. H., Lin C. H., Hwang Y. H., Huan s C. L., Hwang P. P. 2003. Ambient salinity modulates the expressior oi odium pumps in branchial mitochondria-rich cells of Mozambique ti ${ }^{1} a_{1} \downarrow$, Oreochromis mossambicus. Zoological science, 2C, 1, 29-36.

Levental I., Lingwood D., Grzybek M., C skun U., Simons K. 2010. Palmitoylation regulates raft affinity for the lajr city of integral raft proteins. Proc Natl Acad Sci 107:22050-22054.

Lin H., Randall D.J. 1993. $\mathrm{H}^{+}$-ATPas a activity in crude homogenates of fish gill tissue: inhibitor sensitiviıy an a environmental and hormonal regulation. J Exp Biol 180:163-174.

Lin H., Pfeiffer D., Vogl A., Pan J., Randall D. 1994. Immunolocalization of $\mathrm{H}^{+}$-ATPase in th ${ }^{\circ}$ gil epithelia of rainbow trout. J Exp Biol 195:169-183.

Lin Y.M., Chen C.N , Lt :T.H. 2003. The expression of gill Na, K-ATPase in milkfish, Chu. "os chanos, acclimated to seawater, brackish water and fresh water. Comp siochem Physiol A Mol Integr Physiol 135:489-497.

Lin C.H., Huang C.L., Yang C.H., Lee T.H., Hwang P.P. 2004. Time-course changes

in the expression of $\mathrm{Na}, \mathrm{K}-\mathrm{ATPa} e$ and the morphometry of mitochondrionrich cells in gills of euryhaline tilapia (Oreochromis mossambicus) during freshwater acclimation. J Exp Zool Part A 301:85-96.

Lingwood D., Harauz G., Ballantyne J.S. 2005. Regulation of fish gill $\mathrm{Na}^{+}-\mathrm{K}^{+}$-ATPase by selective sulfatide-enriched raft partitioning during seawater adaptation. J Biol Chem 280:36545-36550.

Lingwood D., Simons K. 2010. Lipid raft as a membrane-organizing principle. 
Science 327:46-50.

Liu J., DeYoung S.M., Zhang M., Dold L.H., Saltiel A.R. 2005. The stomatin/prohibitin/flotillin/HflK/C domain of flotillin-1 contains distinct sequences that direct plasma membrane localization and protein interactions in 3T3-L1 adipocytes. J Biol Chem 280:16125-16134.

Madore N., Smith K.L., Graham C.H., Jen A., Brady K., Hall S., Morris R. 1999. Functionally different GPI proteins are organized in different domains on the neuronal surface. The EMBO journal 18:6917-6926.

Mancera J.M., Carrión, R.L., del Rio M.P.M. 2002. Osmoregulatory action of PRL, $\mathrm{GH}$, and cortisol in the gilthead seabream (Sparus aurata L.). Gen Comp Endocrinol 129:95-103.

Marshall W.S. 2002. $\mathrm{Na}^{+}, \mathrm{Cl}^{-}, \mathrm{Ca}^{2+}$ and $\mathrm{Zn}^{2+}$ transport by risı, gills: retrospective review and prospective synthesis. J Exp Zool A E 11 Gंenet Physiol 293:264-283.

Marshall W., Bryson S. 1998. Transport mechani ms ol seawater teleost chloride cells: an inclusive model of a multifunctional celı. 'omp Biochem Physiol A Mol Integr Physiol 119:97-106.

McGuinn, K. P., Mahoney, M. G. 2014. L i nia ^afts and detergent-resistant membranes in epithelial kera` nor ytes. In Epidermal Cells (pp. 133-144). Springer, New York, NY.

Morrow I.C., Rea S., Martin S., Prio» I.A., Prohaska R., Hancock J.F., James D.E., Parton R.G. 2002. Flotillı -1/reggie-2 traffics to surface raft domains via a novel golgi-independ $n t$ pathway. Identification of a novel membrane targeting domain anc' a role for palmitoylation. J Biol Chem 277:48834-48841.

Murtazina R., Kovbasn; ’k (., Donowitz M., Li X. 2006. Na ${ }^{+} / \mathrm{H}^{+} \_$exchanger NHE3 activity and t aftı king are lipid raft-dependent. J Biol Chem 281: 1784517855 .

Musch M.W., Koonıva D.L., Goldstein L. 2004. Hypotonicity-induced exocytosis of the skate anion exchanger skAE1: role of lipid raft regions. J Biol Chem 279:39447-39453.

Neumann-Giesen C., Falkenbach B., Beicht P., Claasen S., Luers G., Stuermer C.A., Tikkanen R. 2004. Membrane and raft association of reggie-1/flotillin-2: role of myristoylation, palmitoylation and oligomerization and induction of filopodia by overexpression. Biochem J 378:509-518.

Neumann-Giesen .C, Fernow I., Amaddii M., Tikkanen R. 2007. Role of EGF-induced tyrosine phosphorylation of reggie-1/flotillin-2 in cell spreading and signaling to the actin cytoskeleton. J Cell Sci 120:395-406.

Nguyen D.H., Hildreth J.E. 2000. Evidence for budding of human immunodeficiency 
virus type 1 selectively from glycolipid-enriched membrane lipid raft. J. Virol. 74:3264-3272.

Nishi T., Forgac M. 2002. The vacuolar $\left(\mathrm{H}^{+}\right)$-ATPases - nature's most versatile proton pumps. Nat Rev Mol Cell Biol 3:94-103.

Ono A., Freed E.O. 2001. Plasma membrane raft play a critical role in HIV-1 assembly and release. Proc Natl Acad Sci USA 98:13925-13930.

Perry S.F., Furimsky M., Bayaa M., Georgalis T., Shahsavarani A., Nickerson J.G., Moon T.W. 2003. Integrated responses of $\mathrm{Na}^{+} / \mathrm{HCO}_{3}{ }^{-}$cotransporters and $\mathrm{V}$-type $\mathrm{H}^{+}$-ATPases in the fish gill and kidney during respiratory acidosis. Biochim Biophys Acta 1618:175-184.

Piermarini P.M., Evans D.H. 2001. Immunochemical analys of the vacuolar proton-ATPase B-subunit in the gills of a euryhali te s ingray (Dasyatis sabina): effects of salinity and relation to $\mathrm{Na}^{+} / \mathrm{K}_{-}^{+}-1$ I rase. J Exp Biol 204:3251-3259.

Pike L.J. 2006. Raft defined: a report on the keyst on symposium on lipid raft and cell function. J Lipid Res 47:1597-1598.

Resh M.D. 2006. Palmitoylation of ligands, ec intors, and intracellular signaling molecules. Sci STKE 2006:re14.

Röper K., Corbeil D., Huttner W.B. ` oOr . Retention of prominin in microvilli reveals distinct cholesterol-based lipid ni-ro-domains in the apical plasma membrane. Nat Cell Biol 2:582-592.

Scheiner-Bobis G. 2002. The soui ın pump. Eur J Biochem 269:2424-2433.

Schroeder R.J., Ahmed S.N., Thu Y., London E., Brown D.A. 1998. Cholesterol and sphingolipid enhanc, the Triton X-100 insolubility of glycosylphosph a $^{+}$dy inositol-anchored proteins by promoting the formation of detergent-ins slub’e ordered membrane domains. J Biol Chem 273:1150-1157.

Schuck S., Honsho ${ }^{\prime}{ }^{\prime}$, Ekroos K., Shevchenko A., Simons K. 2003. Resistance of cell membraıs to different detergents. Proc Natl Acad Sci USA 100:5795-5800.

Scott G.R., Richards J.G., Forbush B., Isenring P., Schulte P.M., 2004. Changes in gene expression in gills of the euryhaline killifish Fundulus heteroclitus after abrupt salinity transfer. Am J Physiol Cell Physiol 287:C300-C309.

Skou J.C., Esmann M. 1992. The Na, K-ATPase. J Bioenerg Biomembr 24:249.

Simons K, Ikonen E. 1997. Functional raft in cell membranes. Nature 387:569-572.

Simons K, Toomre D. 2000. Lipid raft and signal transduction. Nat Rev Mol Cell Biol 1:31-39.

Smart, E. J., Graf, G. A., McNiven, M. A., Sessa, W. C., Engelman, J. A., Scherer, P. E., Okamoto, T., Lisanti, M. P. 1999. Caveolins, liquid-ordered domains, and 
signal transduction. Molecular and cellular biology, 19(11), 7289-7304.

Stuermer C.A.O. 2010. The reggie/flotillin connection to axon growth. Trends Cell Biol 20:6-13.

Stuermer C.A.O, Plattner H. 2004. The "lipid raft"/microdomain proteins reggie-1

and reggie-2 (flotillins) form scaffolds for protein interactions and signaling.

Biochem Soc Symp 72:109-118.

Tang C.H., Lee T.H. 2010. Ion-deficient environment induces the expression of basolateral chloride channel, $\mathrm{ClC}$-3-like protein, in gill mitochondrion-rich cells for chloride uptake of the tilapia Oreochromis ı . sssambicus. Physiol Biochem Zool 84:54-67.

Tillman T.S., Cascio M. 2003. Effects of membrane liriu on ion channel structure and function. Cell Biochem Biophys 38:161-9u.

Toei M., Saum R., Forgac M. 2010. Regulation ar $u_{1}$ slorm function of the V-ATPases. Biochemistry 49:4715-4723.

Uchida K., Kaneko T., Miyazaki H., Hasega va S., Hirano T. 2000. Excellent salinity tolerance of Mozambique tilapia ('recunromis mossambicus): elevated chloride cell activity in the $\mathrm{b}^{r} \mathrm{nnc}^{\prime}$ ial and opercular epithelia of the fish adapted to concentrated seawateı. Zool Sci 17:149-160.

Varma R., Mayor S. 1998. GPI-A ncı red Proteins Are Organized in Submicron Domains at the Cell Surfare. Nature 394:798-801.

von Philipsborn A.C., Ferrer Vaquer A., Rivera-Milla E., Stuermer C.A., Malaga-Trillo E. 2.'5. Restricted expression of reggie genes and proteins during early zet:-afis ^ development. J Comp Neurol 482:257-272.

Welker P., Geist B., 'ruı auf J.H., Salanova M., Groneberg D.A., Krause E., Bachmann S. ?UU7. Role of lipid raft in membrane delivery of renal epithelial $\mathrm{Na}^{+}-\mathrm{K}^{+}-\mathrm{ATr}$ use, thick ascending limb. Am J Physiol Regul Integr Comp Physiol 292:R1328-R1337.

Yang S.H., Kang C.K., Hu Y.C., Yen L.C., Lee T.H. 2015. Comparisons of two types of teleostean pseudobranchs, silver moony (Monodactylus argenteus) and tilapia (Oreochromis mossambicus), with salinity-dependent morphology and ion transporter expression. J Comp Physiol B 185:677-693.

Yoshinaka K., Kumanogoh H., Nakamura S., Maekawa S. 2004. Identification of V-ATPase as a major component in the raft fraction prepared from the synaptic plasma membrane and the synaptic vesicle of rat brain. Neurosci Lett 363:168-172. 


\section{Figure legends}

Fig. 1 Expression of NKA $\alpha$-subunit (NKA) and flotillin-2 protein in lipid raft of fresh water (FW) tilapia gills after digestion with $0.1 \%$ Triton $\mathrm{X}-100$ for 30,60 , and $120 \mathrm{~min}$, as well as $0.05 \%$ Triton $\mathrm{X}-100$ and $0.05 \%$ Tween-20 for $60 \mathrm{~min}$. Immunoblots revealed an immunoreactive band in each condition with a molecular mass of $100 \mathrm{kDa}$ (NKA $\alpha$-subunit) and $48 \mathrm{kDa}$ (flotillin-2). "mem", non-lipid raft; "raft", lipid raft. The tilapia were re ${ }^{\text {" }}$ ’d in brackish water (15 \%o) for two weeks and then acclimated to FW for fou weeks before experiments.

Fig. 2 Expression of NKA $\alpha$-subunit (NKA) and totı in-2 protein in lipid raft of seawater (SW) milkfish gills after di ostion with $0.1 \%$ Triton X-100 for 30, 60 , and $120 \mathrm{~min}$. The immunnhlo ${ }^{\mathrm{s}}$ revealed an immunoreactive band in each condition with a molecular ma ${ }^{-}$of $100 \mathrm{kDa}(\mathrm{NKA} \alpha$-subunit) and $48 \mathrm{kDa}$ (flotillin-2), respectivelv. "m七.n", non-lipid raft; "raft", lipid raft. The milkfish were reared in i rackish water (15\%) for two weeks and then acclimated to $\mathrm{SV} \mathrm{V}^{\top}$ to four weeks before experiments.

Fig. 3 Relative prote; $₫$ a' 'undance of (A) flotillin-2 (Flotillin) and (B) NKA $\alpha$-subunit (NKA) in lip: 1 raft (raft) and non-lipid raft (mem) fractions in gills of seawater (SW) and freshwater (FW) tilapia. The representative immunoblots showed an immunoreactive band in each environment with a molecular mass of (A) $48 \mathrm{kDa}$ (flotillin-2) and (B) $100 \mathrm{kDa}$ (NKA $\alpha$-subunit). The asterisk indicated the significant difference of protein abundance in branchial lipid raft (raft) fractions between the SW and the FW groups. The pound signs indicated significant differences of protein abundance between the lipid raft (raft) and non-lipid raft (mem) fractions of either SW or FW tilapia gills. N/A, 
not detected. $(n=6$, mean \pm S.E.M., t-test, $\mathrm{P}<0.05)$. The tilapia were reared in brackish water (15\%) for two weeks and then acclimated to either FW or SW for four weeks before experiments.

Fig. 4 Relative protein abundance of (A) flotillin-2 (Flotillin) and (B) NKA $\alpha$ - subunit (NKA) in lipid raft (raft) and non-lipid raft (mem) fractions in gills of seawater (SW) and freshwater (FW) milkfish. The representative immunoblots showed an immunoreactive band in each environment with a molecular mass of (A) $48 \mathrm{kDa}$ (flotillin-2) and (P; : $\mathrm{n} \mathrm{kDa}$ (NKA $\alpha$-subunit). The asterisk indicated the significant differen e oi NKA abundance between the SW and FW groups in lipid raft (raft) $\cdots n_{\llcorner}$n-lipid raft (mem) fractions. The pound signs indicated significant difier nces of protein abundance between the lipid raft (raft) and no $n-\because n d$ raft (mem) fractions of either SW or FW milkfish gills. N/A, is ${ }^{\prime}$.etected. $(n=6$, mean \pm S.E.M., t-test, $\mathrm{P}<$ 0.05). The milkfish were ru red in brackish water (15\%) for two weeks and then acclimated to either $\mathbf{T} /$ or $\mathrm{SW}$ for four weeks before experiments.

Fig. 5 Relative protein a乞 'n lance of V-type $\mathrm{H}^{+}$-ATPase A subunit (VHA A) in lipid raft (raft) $\wedge^{\wedge}$ a ..un-lipid raft (mem) fractions in gills of seawater (SW) and freshwater (FW) tilapia. (A) The representative immunoblot showed an immunoreactive band in each group with a molecular mass of $68 \mathrm{kDa}$. (B) The asterisks indicated significant differences of VHA A abundance between the SW and FW groups in lipid raft (raft) or non-lipid raft (mem) fractions. The pound signs indicated significant differences of VHA A abundance between the lipid raft (raft) and non-lipid raft (mem) fractions of either SW or FW tilapia gills. N/A, not detected. $(n=6$, mean \pm S.E.M., t-test, $P<0.05)$. The tilapia were reared in brackish water (15\%) for two weeks and then 
acclimated to either FW or SW for four weeks before experiments.

Fig. 6 Relative protein abundance of V-type $\mathrm{H}^{+}$-ATPase A subunit (VHA A) in lipid raft (raft) and non-lipid raft (mem) fractions in gills of seawater (SW) and freshwater $(\mathrm{FW})$ milkfish. The representative immunobglot of V-type $\mathrm{H}^{+}$-ATPase A subunit (VHA A) showed two bands at molecular weights of 69 $\mathrm{kDa}$ (isoform 1) and $60 \mathrm{kDa}$ (isoform 2) (A). Rel tivf protein abundance of VHA A isoform 1 (B) and isoform 2 (C) revc. led the significant difference indicated by the asterisk between the SW an $\mathrm{FW}$ groups in non-lipid raft (mem) fractions of gills. Mea . . h1 . the pound signs indicated significant differences in VHA A iso 7 rm 1 (B) and isoform 2 (C) between the lipid raft (raft) and non-lipid r... $\left(n_{n}\right.$ m) fractions of either SW or FW milkfish gills. (n $=6$, mean \pm S.E.1r, เ test, $\mathrm{P}<0.05)$. The milkfish were reared in brackish water $(1 \% \%$, fo two weeks and then acclimated to either FW or SW for four weeks before experiments. 


\section{Highlights}

1. Lipid raft were extracted from gills of teleosts using nonionic detergents.

2. Flotillin-2 expression is differently affected by salinity among teleost species.

3. $\mathrm{Na}^{+}, \mathrm{K}^{+}$-ATPase is mainly located in lipid raft fractions enriched in flotillin-2.

4. V-type $\mathrm{H}^{+}$-ATPase is expressed in both, non-lipid raft and lipid raft fractions.

5. Salinity affects V-type $\mathrm{H}^{+}$ATPase expression in non-lipid raft fractions only. 


\section{$0.1 \%$ Triton $\mathrm{X}-100$}

$$
\begin{aligned}
& \min \\
& \mathrm{kDa} \\
& 130- \\
& 100- \\
& 72- \\
& 55- \\
& 43-
\end{aligned}
$$

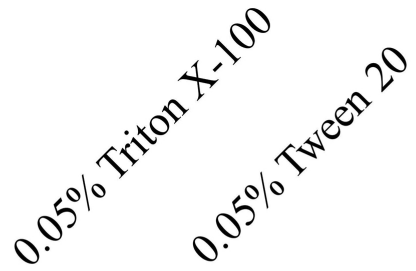

120
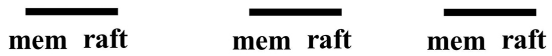

Figure 1 


\section{$0.1 \%$ Triton $\mathrm{X}-100$}

$\begin{array}{llll}\min & 30 & 60 & 120\end{array}$

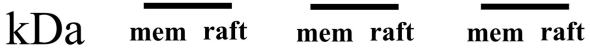

$130-$

$100-$

$72-$

$55-$

43-

\section{- Flotillin-2}

Figure 2 
(A) $\mathrm{kDa}$

(B) $\mathrm{kDa}$

55 -

43-

- Flotillin

34-

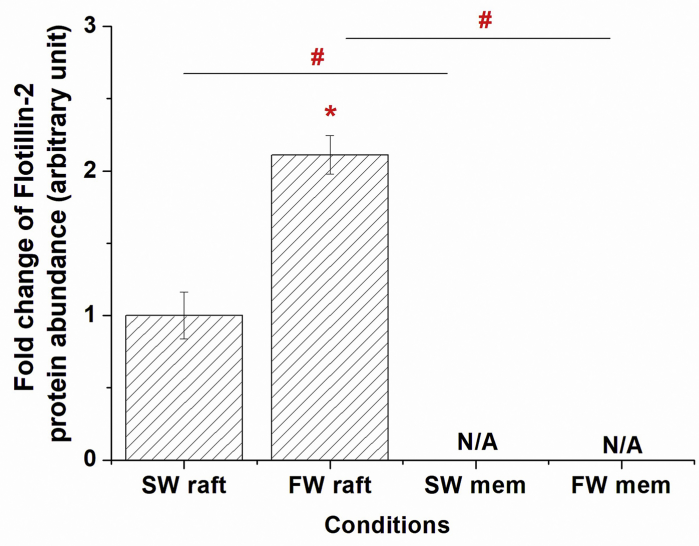

130 -

$100-$

- NKA

72-

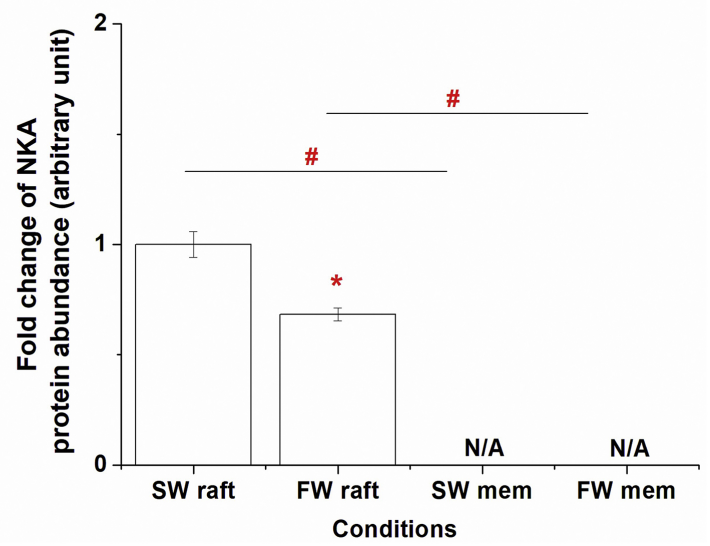

Figure 3 
$\mathrm{kDa}$

$55-$

43-

- Flotillin

34-

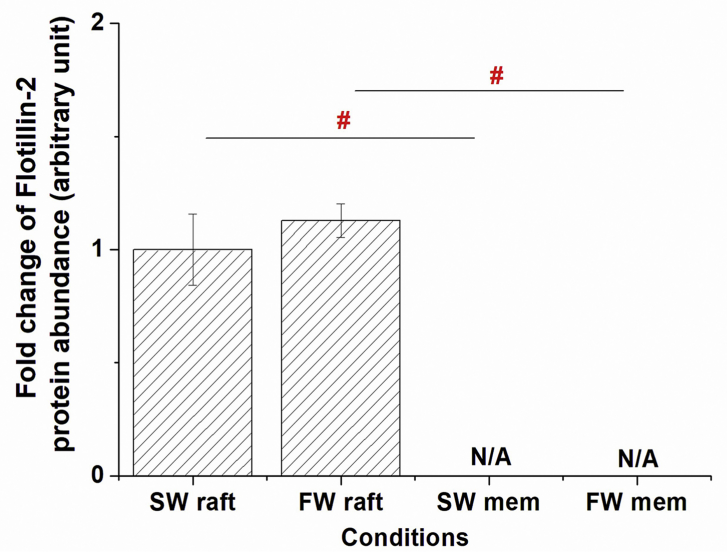

$\mathrm{kDa}$

130 -

100- weer mo - NKA 72-

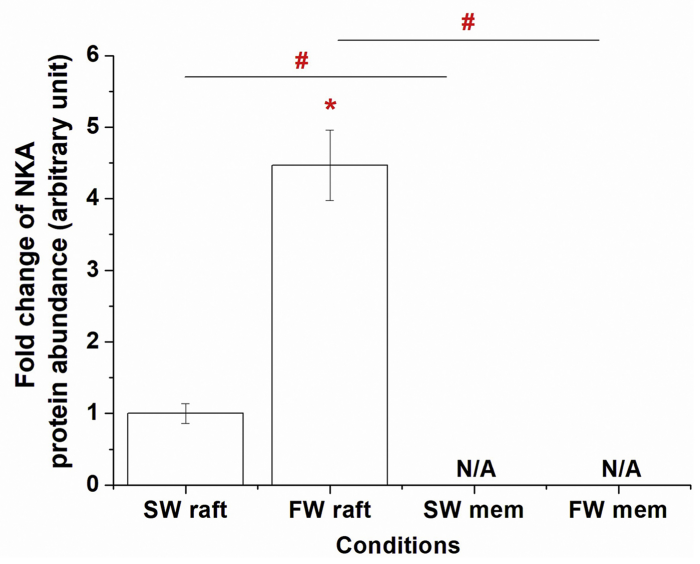

Figure 4 
(A)

$\mathrm{kDa}$

100

$75-$

$60-$

(B)

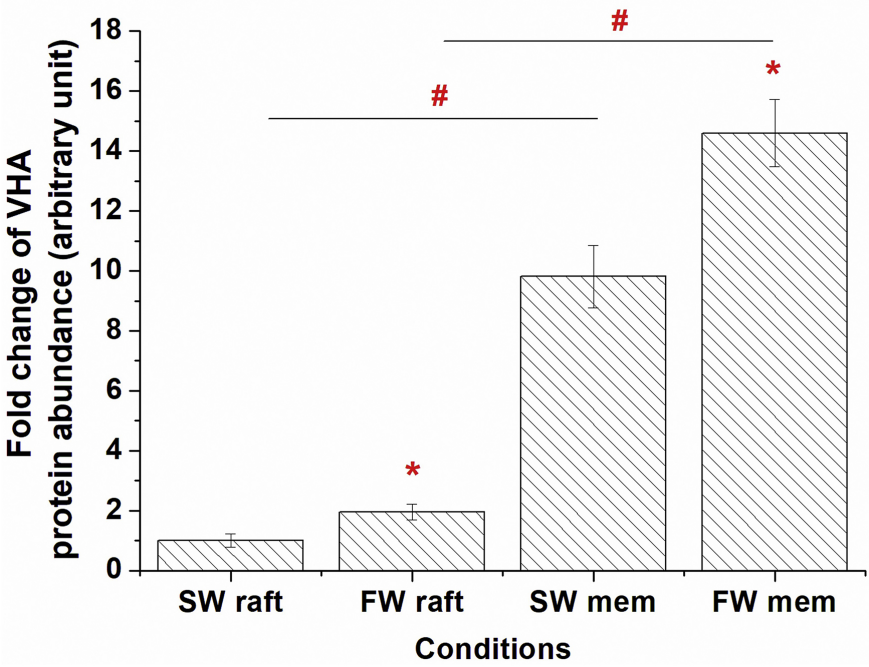

Figure 5 
(A) $\mathrm{kDa}$

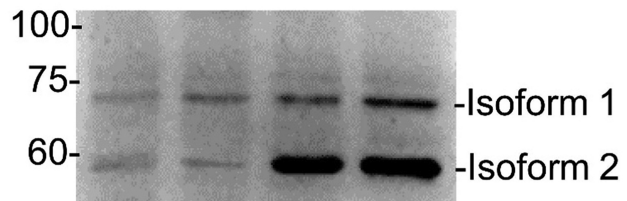

(B)

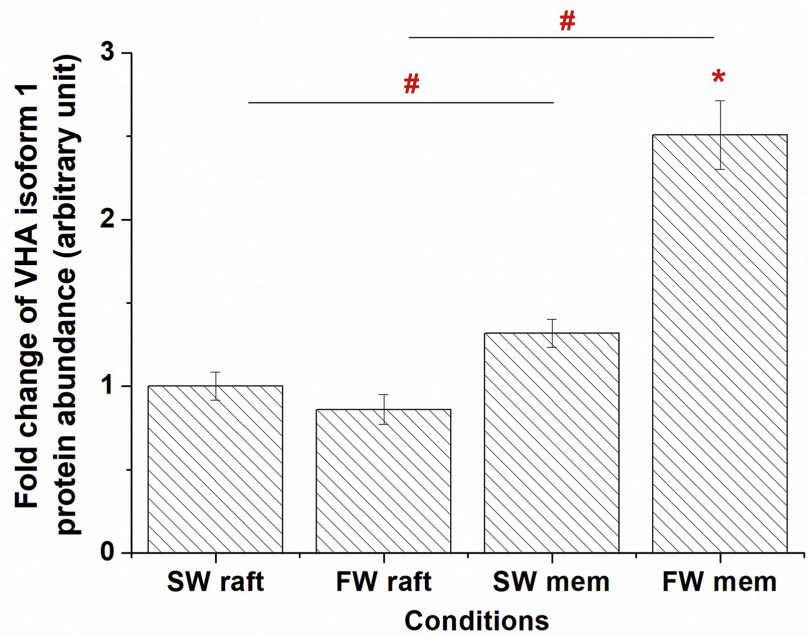

(C)

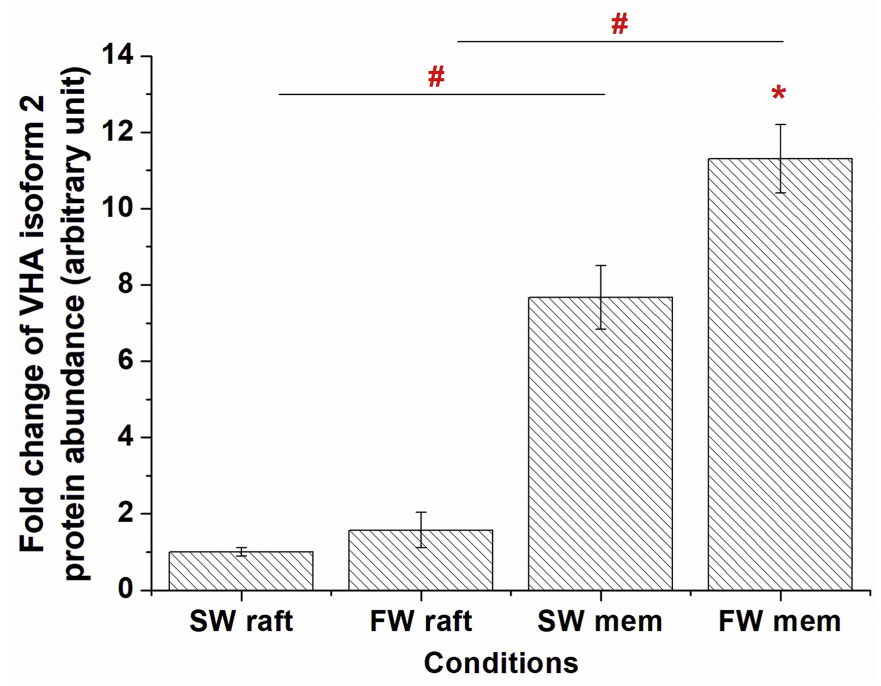

Figure 6 